\title{
The Investigation of Translator Subjectivity in Publicity Translation Based on Teleological View
}

\author{
Jun Zhao ${ }^{1, \text { a }}$ \\ ${ }^{1}$ Neijiang Normal University, Neijiang, Sichuan Province, China \\ a54411234@qq.com
}

Key words: Publicity Translation, Translation, Teleological, Translator, Subjectivity.

\begin{abstract}
The translator of the original composition is audience, but it is also a reproduction of the original creative person. The language cultural differences between original language and target language, image propaganda language, language vivid, translators provide a broad creative space for translator. To maximize the reappearance of the original artistic beauty, this article investigates the translator subjectivity in publicity translation based on teleological view. The result shows that the subjectivity of the translator is indispensable.
\end{abstract}

\section{Introduction}

Traditional theoretical studies tend to overemphasize the translation between the original and the like, generally ignored the propaganda of literature translation and translation studies as the main body of the translator [1]. With Translation Studies "cultural turn" in translation studies and gradually by the body the attention it deserves, we will continue to go deeper. As early as the 1980s and 1990s on the translator's status and role that deliver a brilliant exposition, and emphasis on the translation subject the importance of research. "The subject of translation, that translation home; only the translators as spiritual and mental aspects of people also included field observation, it may reach a variety of answers to the delicate question of the nature of literature translation” [1].

Translator is a translation of the body, which seems to be an indisputable fact. Translation is divided into two processes, namely the process of understanding of the original and the reproduction of the original process, which is the first use of the translator's own analytical thinking ability in its original language materials, traces the author's ideas, and then integrated the target language means reproduced in its original language [1]. Both in understanding the stage or in the stage of expression, and translation activities are the principal factors translator closely linked. The so-called "subjectivity", specifically refers to "the subject in the object nature of sexual activity outside of power, and dynamically transforming the object, the impact of the object, the control object so that the object serving as the main feature." Then the main body of the translator is a translator translate object in respect of the premise, in the translation process embodied in the initiative, which is reflected in the translation of the conscious personality and aesthetic creativity. Publicity translation is probably all translations of the most amorphous, most unpredictable, and most difficult to grasp the need for a creative translation. Propaganda text compared to plain text, on the one hand to provide readers with the potential for a broader interpretation of aesthetics and space, on the other hand more subject to linguistic form. Thus, the main body of the Translator's propaganda was particularly prominent. This paper attempts to explore Publicity Translation Subjectivity from the teleological perspective [2].

\section{The features of publicity translation}

Publicity translation in the target language readers who aimed to generate good publicity for the business and establish a good image, to induce potential customers desire to buy, and therefore belongs to the stimulation of the receiver to take "infected text" some kind of action. Meanwhile, Publicity translation also needs to target readers objectively shows the real performance advantages of the product and, therefore, has a characteristic "message text" is. Since Publicity translation 
utility, both texts types of characteristics, to achieve the desired propaganda effect "infected text" feature should dominate [2]. Therefore, in the translation propaganda text, on the one hand to accurately reflect the true objective quality characteristics, on the other hand, it is a more important aspect is to cross language and cultural differences between the source language and the target language, the use of alternative translation methods, closer to the psychological distance between the reader and the target language, so that they produce to maximize the product's identity, to achieve positive good publicity, induce more potential customers. This should be the guiding ideology translation of such texts.

Publicity material translated publicity generally divided into three levels. The first level is the understanding that through the effective transfer of information, the reader quickly understands the quality of products and services through outreach data translation. The translator should pay attention to the process of objective information, true, accurate, clear and concise language, as soon as possible in order to eliminate the strangeness readers. This is the lowest level is the most basic translation propaganda effect, but it laid the foundation for a higher level of publicity. The second level is acceptance that the target reader in understanding the product on the basis of product quality and service with psychological and cultural identity [2]. To achieve this level, the translator of the process required to transfer attention to the language and cultural information, and try to eliminate cultural exclusion and conflict information, to narrow the psychological distance to get the target readers psychological identity. It is propaganda translated intermediate level and intermediate effect, plays the role of connecting to potential customers for paved roads. The third level is the lure move that target readers through the first two levels of bedding, attracted by the product, with the desire to shop. To achieve this level, the translator of the process required to rhetorical emphasis on multilingualism, give full play to the validity of the language, the purpose of guiding action. It is the highest level of translation propaganda and the ultimate effectiveness of the publicity, so that the customers from the heart into action [3]. Each of these three levels is a propaganda text should simultaneously consider and try to achieve the effect; they are closely linked and inseparable, and progressive layers. Here, we choose several English translations of Chinese propaganda discourse to illustrate how each level is achieved buying behavior caused by different translation strategies and methods. It should be noted that, in the actual process of translation, which is three levels of contact simultaneously and overlap, and they cannot be separated, but in the course of the study for a clearer explanation of the different levels of publicity and translation, we will discuss them separately.

The translator is the propaganda of the original text reader. Acceptance activities are so prescriptive that two opposing unification process. Reading is a dynamic two-way communication process, on the one hand, to provide readers with original guidance; on the other hand, under the guidance of the original reader according to their own understanding of the construct meaning, in this two-way communication, the reader of the text is not a simple " recovery ", but a creative" reform "readers in the process of making the text of the potential for their own services, not only made a call aesthetic potential, but also for their aesthetic potential of adding new energy [3]. To improve the reader's initiative, creativity, the translation and the translator as the readership of the text can understand the interpretation of the original. In understanding the interpretation process, the translator need to mobilize their emotions, will, aesthetics, imagination and other propaganda appreciation and criticism propaganda ability to explore the ideological content and aesthetic implication of the work, the work of the "blank spots" specific, a Text Construction complete sense. Text reading is often a individual behavior, different readers because of their own literacy, life experience, the difference virtuosity and aesthetic appeal as well as look at the issue from different perspectives, specific results of the same text varies, different translator for the same understanding of the text will be different, even very different. Therefore, the translator of the acceptance process is to re-create the original text of the process, only the process in order to make propaganda work to be truly original [4]. On the other hand, the translator and the general reader different, because responsibility to convey the original text, the translator when reading in the preservation of the integrity of the original premise, will find ways to tap the potential significance of the work, the 
reading itself has a very strong initiative.

Translator is a reproduction of the original main propaganda text. Ethnic differences in aesthetic taste, aesthetic expression of such functional language forms are also different [4]. Outreach work is the language of art creation, in almost all things artistic, are its unique personality show its vitality, a propaganda work more distinct personality, its propaganda value will be higher, the more communicated limitations large, the more the need to create a translator. The main function of propaganda is to give people inspiration, beauty and strength, people read propaganda works, not only want to know the story, but also want to enjoy the language arts. A foreign propaganda work, if it does not translate propaganda taste, no matter how it is regrettable to say. So, as a translator fluent in foreign propaganda in addition to translation in both languages, but also needs to have a writer's propaganda training, writing skills and image thinking ability [5]. In the original text of the reproduction process, through the language of the original shape, deeply appreciate the author's artistic process, to grasp the spirit of the original, and then the "target language play advantage", suitable for the use of the original language of propaganda, for proper angle conversion and language work, the original ideological content and artistic style correctly reproduced, in order to achieve the best artistic effect. The following is a translation of the translator to do so.

German psychologists and linguists will Biller semantic function of language is divided into three categories, namely "reproduction" function, "expression" function and "infection" function. The "reproduction" function means "sign language objectively reproduce things", "expression" refers to the function "sign language to express the sender's subjective state of mind", "infection" function means "moving sign language, feelings or outside influence the recipient in action " [5].

In Table 1, Royces summed up the three different types of text language features, characteristics and language translation purposes in the publicity translation, text translation methods and specific focus for us in translation practice depending on the type of text choose a different translation strategies provide a more workable theory [6]. As can be seen from the table, the translation of the text message should be "faithful" to the source text of an objective factual content, through clear and concise language, complete direct delivery of content, translation and the original amount of information to achieve peer. Translation expression text should be "faithful" to the source language of the sender, by emulating the original author, highlighting the original form and emotion, realize translation and the original form of artistic expression and emotion and so on [6]. Text translation infection should be "faithful" to the recipient of the translation of the text by using the compiler, change of translation and other translation skills, infection results highlight the translation, to achieve the effect of translation and the original readers who generated peer.

Table.1 Publicity translation key points

\begin{tabular}{cccc}
\hline Text type & Informative & Expressive & Operative \\
\hline $\begin{array}{c}\text { Language features } \\
\text { Information }\end{array}$ & $\begin{array}{c}\text { Expression of } \\
\text { things and facts }\end{array}$ & Express feelings & Infected recipients \\
\hline Text Focus & Focus on content & Focus on the form & $\begin{array}{c}\text { Focusing on the } \\
\text { role of infection }\end{array}$ \\
\hline Translation purposes & $\begin{array}{c}\text { Expression of its } \\
\text { contents }\end{array}$ & $\begin{array}{c}\text { The performance } \\
\text { of its form }\end{array}$ & $\begin{array}{c}\text { Elicit a desired } \\
\text { response }\end{array}$ \\
\hline Translation & $\begin{array}{c}\text { With simple } \\
\text { vernacular }\end{array}$ & $\begin{array}{c}\text { Follow faithfully } \\
\text { the original author }\end{array}$ & $\begin{array}{c}\text { Equivalent to the } \\
\text { original }\end{array}$ \\
\hline
\end{tabular}




\section{The Creative Publicity Translation Translator}

Publicity discuss Translator 'creative problem, we must first understand the purpose of the translation of foreign propaganda work in the end what is the problem. We believe that the translation should be pure propaganda rooted in the art of text into exotic territory of special energy to another aesthetic subject cultural traditions and cultural environment acceptable and have the same effect artistic text, reproducing the original artistic beauty, let the target readers achieve the same with the original readers of aesthetic experience, which is the main purpose pure propaganda translation [7]. Due to the heterogeneity of language form, language and other cultural barriers between propaganda translations especially poetry translation is very difficult, sometimes untranslatable. Difficult to do this, even untranslatable and translation, then reproduce the original in order to achieve the purpose of artistic beauty, while the translator must be faithful to the original, the original bound by; on the other hand they have to jump out of the shackles of language level, binding target language linguistic and cultural backgrounds, to rethink within the framework of the original, the original content of cultural meaning and spiritual re-creation, the only way to translate the both faithful to the original, but also for the target language readers accepted good translation . Therefore, the translator of creative activity is essential [7]. Due to differences in language structure, propaganda cannot pursue every word translation corresponds to sentence copy, Publicity faithful translation is faithful ideological content, the translator's creativity is reflected in the language of forms and styles of re-creation, link two - Examples:

\section{Summary}

This article on the subject of propaganda translation process embodied translator were beginning to explore a little, in fact, it is an independent translator of individual consciousness, but subject to the restrictions of the original objective, so he needs to grasp the original multi-consciously meaning, while playing language use initiative. Translator creativity should be reflected in how to express the original content with acceptable target language, reproducing the original artistic beauty. Subjectivity translator is bound to exist, the translator should grasp the good balance between the subjectivity and objectivity of its text, undue restraint creative impulse in the translation, they act without more regulation, to maximize the reappearance of the original artistic beauty. Not a good translation of the original betrayal, but the same thing with the original, at the right time can also be icing on the cake, even better than the original.

\section{Acknowledgement}

Fund project: This project, Research on C-E Translation for Publicity Translation in Perspective of Skopos Theory, is supported by Foundation for Scientific Research of Education Department of Sichuan Province. Project No.: 15SB0144.

\section{References}

[1] Y. Wu, Pride and self-esteem with ease embarrassment--translator Psychology of Personality propaganda, Chinese translation, 2013, vol.2, pp.54-57.

[2] Y.L. Wang, On the basic connotation and characteristics of subjectivity, Tianfu new theory, 2005, vol.6, pp.32-38.

[3] S.R. Yi, Reading activities--aesthetic response theory, Beijing: China Social Sciences Publishing House, 2011, vol.29, pp.11-15.

[4] S.Y.Zhang, On the History of the Twentieth Century West, Beijing: Peking University Press, 2009, vol.2, pp.80-83. 
[5] Ch.Y. Yuan, Re-creation and translation style, PLA UNIVERSITY OF FOREIGN LANGUAGES, 2010, vol.5, pp.46-51.

[6] Zh.Sh. Qian, Seven sets decorated, Shanghai: Shanghai Ancient Books Publishing House, 1994, 81-86.

[7] W. Chen, The establishment of "identity" propaganda translation, Chinese translation, 2007, vol.1, pp.58- 62. 